\title{
The Impact of Patient Support Programs on Adherence to Disease-Modifying Therapies of Patients with Relapsing-Remitting Multiple Sclerosis in Germany: A Non-Interventional, Prospective Study
}

Florian Lenz · Lutz Harms

Received: February 26, 2020 / Published online: April 24, 2020

(C) The Author(s) 2020

\section{ABSTRACT}

Introduction: Disease-modifying therapies (DMTs) in multiple sclerosis (MS) are chronic therapies, and patients are likely to face challenges in adhering to DMT dosing regimens over time. DMT manufacturers offer patient support programs (PSPs) to increase adherence. PSPs are managed offerings typically encompassing nurse services, phone services, online resources, or mobile offerings. This study evaluated whether PSPs have a positive impact on adherence to DMTs among patients with mildto-moderate relapsing-remitting multiple sclerosis (RRMS) in Germany, independent of the treatment duration on DMT.

Methods: This was a non-interventional, prospective, cross-sectional, multi-center study with patient-reported outcomes. Patients reported their DMT adherence using patient adherence questionnaires at four visits during an observation period of 24 weeks; PSP participation for this period was reported at the last visit. The primary objective was to evaluate the impact of PSPs on adherence across different

Digital Features To view digital features for this article go to https://doi.org/10.6084/m9.figshare.12124170.

F. Lenz · L. Harms $(\bowtie)$

Department of Neurology With Experimental

Neurology, Charité-Universitätsmedizin Berlin, Berlin, Germany

e-mail: ms-ambulanz@charite.de
DMTs by comparing patients with PSP participation versus no participation; adherence was defined as not missing a single dose of DMT.

Results: One hundred eighty-four patients were analyzed (mean age: 44.6 years; $73.4 \%$ female; mean time on DMT: 7.2 years). Adherence across DMTs was significantly higher for PSP participants $(92.9 \%)$ compared with nonparticipants $(61.8 \%)(P=0.0197)$. The observed rate of PSP participation (7.6\%) was significantly lower than reported in earlier studies $(P<0.0001)$; PSP awareness among patients analyzed was low (22.3\%).

Conclusion: We consider this study to have shown that PSPs have a positive impact on adherence to DMTs in MS, independent of the treatment duration on DMT. The majority of PSP participants also believe in this positive effect. PSP participation and patient awareness were low, and real-world adherence levels were found to be higher with self-injectable DMTs than with oral DMTs. In summary, physicians should actively advise patients with MS to participate in PSPs and, together with their patients, consider achievable real-world adherence under different DMTs when deciding MS treatment strategies.

Keywords: Adherence; Compliance; Diseasemodifying therapy; Multiple sclerosis; Patientreported; Patient support program; Patient service; Real-world 


\section{Key Summary Points}

Why carry out this study?

Patients and healthcare professionals commonly consider patient support programs (PSPs) to increase adherence to disease-modifying therapies (DMTs) in multiple sclerosis (MS). PSP impact has been evaluated mostly for persistence (continuation) and for single DMTs, less for adherence (DMT dosing behavior over time) and across a spectrum of DMTs.

The aim of this study was to evaluate whether PSPs have a positive impact on adherence across a range of DMTs for firstline treatment of relapsing-remitting multiple sclerosis (RRMS), independent of the treatment duration, in a real-world setting in Germany.

\section{What was learned from the study?}

PSPs have a positive impact on adherence to DMTs, independent of the treatment duration on DMT.

PSP participation and patient awareness were low; real-world adherence levels were found to be higher with self-

injectable DMTs than with oral DMTs.

In conclusion, physicians should actively advise patients with MS to participate in PSPs and, together with their patients, consider achievable real-world adherence under different DMTs when deciding MS treatment strategies.

\section{INTRODUCTION}

\section{Multiple Sclerosis Therapies}

Multiple sclerosis (MS) is a chronic, autoimmune inflammatory disease of the central nervous system characterized by relapsing disease activity and eventually progressive degeneration [1]. The majority of patients (85-90\%) present with relapsing-remitting multiple sclerosis (RRMS) at onset; for RRMS the periodic acute relapse followed by remission is the exclusive clinical expression without clinical disease progression. RRMS may convert to a secondary progressive MS over time. In 10-15\% of patients a primary progressive form of MS is diagnosed at onset [2]. MS prevalence in Germany is approximately $120,000-224,000$ cases, making MS the most common chronic disease of the central nervous system [3-5].

A curative treatment for MS does not exist. Disease-modifying therapies (DMTs) are the mainstay of current treatment strategies and aim at reducing the inflammation resulting in relapses and potentially disability progression [6]. Recent years have seen a large expansion in DMTs available in Europe, with 12 drugs approved by the end of 2017 [7, 8]. The spectrum of DMTs with (patient) self-injectable, infusion and oral formulations offers expanded opportunities, but adds complexity as several factors need to be considered in clinical practice: mechanism of action, risk profiles, route of administration, monitoring requirements, or patient expectations and routines [9]. DMT regimens differ by dosing frequency and complexity, and their integration in daily routines of patients with MS is important for successful treatment execution. German MS guidelines support the first-line treatment of RRMS patients with mild-to-moderate disease activity with self-injectable and oral DMTs as listed in Table 1 [4].

\section{TREATMENT ADHERENCE}

DMTs are chronic therapies administered on an ongoing basis. Patients are likely to face challenges in adhering to the prescribed DMT dosing schedule; adherence leads to better clinical outcomes [10-12]. Adherence differs from persistence: persistence is most commonly reported as patients either discontinuing treatment or showing significant gaps in treatment execution, whereas the concept of adherence rates encompasses the actual amount of DMT doses 
Table 1 Self-injectable and oral DMTs

\begin{tabular}{|c|c|c|c|}
\hline Type & Active substance & Dosing regimen, formulation & DMT brand name, manufacturer ${ }^{a}$ \\
\hline \multirow[t]{5}{*}{ Self-injectable DMT } & Glatiramer acetate sc & $20 \mathrm{mg} \mathrm{od} / 40 \mathrm{mg}$ tiw & Clift ${ }^{\circledR}$, Mylan; Copaxone ${ }^{\circledR}$, Teva \\
\hline & Interferon beta-1a im & $30 \mu \mathrm{g}$ weekly & Avonex ${ }^{\circledR}$, Biogen \\
\hline & Peg-interferon beta-1a sc & $125 \mu \mathrm{g} \mathrm{q} 2 \mathrm{w}$ & Plegridy®, Biogen \\
\hline & Interferon beta- $1 \mathrm{a}$ sc & $22 / 44 \mu \mathrm{g}$ tiw & Rebif ${ }^{\circledR}$, MerckSerono \\
\hline & Interferon beta- $1 \mathrm{~b} \mathrm{sc}$ & $250 \mu \mathrm{g} \mathrm{eod}$ & Betaferon ${ }^{\circledR}$, Bayer; Extavia ${ }^{\circledR}$, Novartis \\
\hline \multirow[t]{2}{*}{ Oral DMT } & Dimethyl fumarate & $240 \mathrm{mg}$ twice daily & Tecfidera ${ }^{\circledR}$, Biogen \\
\hline & Teriflunomide & $14 \mathrm{mg}$ od & Aubagio ${ }^{\circledR}$; Sanofi-Genzyme \\
\hline
\end{tabular}

$S c$ subcutaneous, im intramuscular, od once daily, tiw three times weekly, $q 2 w$ every 2 weeks, eod every other day

${ }^{a}$ Brand names are registered trademarks

administered by patients over a defined period of time, including possible non-persistence [13].

Adherence rates published for self-injectable DMTs range from 49 to $88 \%$, depending on the study design and definition of adherence rates, and show sensitivity to dosing frequency/complexity and route of administration. Most common factors for non-adherence are forgetfulness, lack of motivation and treatment side effects [13-15]. The recent introduction of oral DMTs was expected to benefit adherence; however, adherence rates, sensitivity to dosing frequency/complexity and factors for non-adherence have been shown to be rather comparable to those for self-injectable DMTs [16-18].

DMT non-adherence is directly affected by patient beliefs and behaviors. There is an unmet need for effective care management and support. DMT manufacturers pursue different strategies to support adherence including simplification of formulation/dosing regimens, innovative injectable devices and commonly offered patient support programs (PSPs).

\section{Patient Support Programs}

PSPs are managed service offerings provided by DMT manufacturers; a unique definition does not exist, and PSP implementation in Europe is subject to individual country regulation. PSPs are optional services beyond insured standard of care and aim at directly educating patient beliefs and behaviors to increase adherence.

In Germany, DMT manufacturers offer PSPs with different services types (see Table 2); details such as content, communication channels or third-party service partnerships may vary between manufacturers and individual DMTs. Patients are typically enrolled in cooperation with MS centers and selected service types may only be accessible for patients treated with an individual DMT [19-25]. Data on PSP participation in MS are limited; participation rates in studies range from 37-70\% in Germany and other countries $[26,27]$. DMT manufacturers in Germany cited participation rates of up to $75 \%$.

\section{Study Interest}

Patients and healthcare professionals commonly consider PSPs to increase adherence. PSPs have been evaluated for their impact on persistence following treatment initiation or for patient satisfaction, mostly for single DMTs, and in different countries [26-31]. The aim of this study was to evaluate whether PSPs have a positive impact on adherence to DMTs supported for first-line treatment in mild-to-moderate RRMS in Germany across a spectrum of different therapies, independent of the treatment duration on DMT. 
Table 2 Manufacturer PSPs in Germany

\begin{tabular}{llllll}
\hline Manufacturer & PSP name $^{\mathbf{a}}$ & \multicolumn{2}{l}{ PSP service types } \\
\cline { 3 - 6 } & & $\begin{array}{l}\text { Nurse } \\
\text { services }\end{array}$ & $\begin{array}{l}\text { Phone } \\
\text { services }\end{array}$ & $\begin{array}{l}\text { Online } \\
\text { resources }\end{array}$ & $\begin{array}{l}\text { Mobile } \\
\text { offerings }\end{array}$ \\
\hline Bayer & Betaplus, MS Gateway [19] & $\mathrm{X}$ & $\mathrm{X}$ & $\mathrm{X}$ & $\mathrm{X}$ \\
Biogen & MS Life, GemeinsamStark [20] & $\mathrm{X}$ & $\mathrm{X}$ & $\mathrm{X}$ & $\mathrm{X}$ \\
MerckSerono & Adveva (Rebistar) [21] & $(\mathrm{X})$ & $\mathrm{X}$ & $\mathrm{X}$ & $\mathrm{X}$ \\
Mylan & Mein MS Service [22] & $(\mathrm{X})$ & $\mathrm{X}$ & $\mathrm{X}$ & \\
Novartis & MSUNDICH, Extracare [23] & $\mathrm{X}$ & $\mathrm{X}$ & $\mathrm{X}$ & $\mathrm{X}$ \\
Sanofi- & MS Begleiter [24] & $(\mathrm{X})$ & $\mathrm{X}$ & $\mathrm{X}$ & $\mathrm{X}$ \\
\multicolumn{1}{c}{ Genzyme } & & & & & \\
Teva & Aktiv mit MS [25] & $\mathrm{X}$ & $\mathrm{X}$ & $\mathrm{X}$ & $\mathrm{X}$ \\
\hline
\end{tabular}

" $\mathrm{X}$ " for confirmed, " $\mathrm{X})$ " for indicated service type availability; not all services may be continuously available

${ }^{a}$ PSP names may be registered trademarks

b Service type information per public sources

\section{METHODS}

\section{Study Design}

This was a non-interventional, prospective, multi-center study evaluating the impact of PSPs on adherence to DMTs supported for firstline treatment in mild-to-moderate RRMS in Germany as assessed by patient-reported outcomes. Eight participating MS centers enrolled patients and asked them to complete either paper-based or electronic case report forms of the DMT patient adherence questionnaire (PAQ), with Charité as coordinating study center.

Patients were eligible if $18-60$ years of age, with a confirmed diagnosis of mild-to-moderate RRMS and treated with a DMT listed in Table 1. DMT dosages were per national requirements. Patients were enrolled independent of their time on current DMT or a prior treatment with other DMTs. Exclusion criteria encompassed severe cognitive impairment, RRMS with high disease activity and primary or secondary progressive MS.

Ethics committee approvals were obtained before study initiation from Charité Universitätsmedizin Berlin and the State Chamber of
Medicine Brandenburg. All patients provided written informed consent for study participation and data processing.

\section{Analytical Objectives and Model}

The primary objective of this study was to evaluate whether PSPs have a positive impact on adherence across different DMTs by comparing patients with PSP participation ("participants") versus patients without PSP participation ("non-participants"). Adherence was defined as not missing a single dose of DMT $(100 \%)$ at each visit of the observation period, measured with the PAQ. A consensus on an acceptable level of DMT adherence does not exist; most studies use cutoff levels of $80-100 \%$ $[14,15]$. We decided to use the $100 \%$ threshold to provide adequate sensitivity for our study objectives. Secondary objectives were to evaluate patient participation levels in PSPs and participants' use of PSP service types and beliefs in PSP effects.

Statistical significance was tested at an $\alpha$ level of 0.05 . Normally distributed data were analyzed using variance models. For continuous, not normally distributed data the Mann-Whitney $U$ test and for dichotomous/ 
binary data either the chi-square or binomial test was used. Statistical analysis was performed using SPSS version 26 software.

\section{Protocol and Patient-Reported Outcomes}

The study sites obtained written informed consent from the patients prior to initiating any study-related procedure. They enrolled eligible patients, documented inclusion and exclusion criteria, medical history and medication, and asked patients to answer the PAQ at four visits during the observation period of 24 weeks (168 days). The study sites made no study-related active indication for a PSP participation to patients.

Patients received the paper-based or electronic PAQ directly from and reported directly to Charité. The PAQ for visit 1 to visit 4 included 16 questions covering DMT dosing behavior and patient beliefs for a 14-day period before each visit. The PAQ for visit 4 comprised an additional 12 questions covering PSP participation during the whole observation period.

\section{RESULTS}

\section{Participants and Patient Support}

Two hundred seventeen patients were enrolled by eight MS centers over a 10-month period. Data were analyzed for 184 patients; 103 (56.0\%) patients reported with paper-based and $81(44.0 \%)$ with electronic case report forms. Thirty-three patients were excluded from analysis: 16 patients did not report any data, 11 discontinued reporting (of which 3 continued on DMT and 1 discontinued DMT; for 7 no information was available), and 6 had conflicting data (of which 3 changed DMT during reporting). Of the 184 patients analyzed, 118 $(64.1 \%)$ patients were treated with self-injectable DMTs and 66 (35.9\%) with oral DMTs (Table 3). Patients were well matched by individual DMT versus country-specific treatment practices. PSP offerings were available during the observation period as shown in Table 2 .
Of the 184 patients analyzed, 14 (7.6\%) reported a PSP participation; 170 (92.4\%) patients reported no PSP participation, including $27(14.7 \%)$ reporting an active decision against a PSP participation and 143 (77.7\%) reporting no awareness of a PSP offering (data not shown). PSP participants and non-participants were statistically comparable in age, gender, duration on current DMT and total duration on DMT $(P=0.53 ; 0.86 ; 0.86 ; 0.77)$ and well distributed across MS centers; DMT duration data reflected the cross-sectional study characteristics. PSP participation varied across DMTs and was higher for patients treated with self-injectable DMTs (11.0\%) compared with oral DMTs (1.5\%); it was highest with glatiramer acetate (GA) $40 \mathrm{mg}$ Teva (24.0\%) and interferon (INF) beta-1b sc Bayer (13.3\%) and lowest with INF beta-1a im, INF beta-1b sc Novartis and dimethyl fumarate $(0 \%)$.

The observed PSP participation rate for all DMTs $(7.6 \%)$ was significantly lower [-29.4 percent points (pp); $P<0.0001]$ than data from a real-world study with a self-injectable DMT at 12-month follow-up in Germany (37\%) [26]; versus these reference data, participation was significantly lower $(-26.0 \mathrm{pp})$ for self-injectable DMTs $(11.0 \% ; P<0.0001)$ and lower $(-13.0 \mathrm{pp})$ for the highest reported participation for an individual DMT (GA $40 \mathrm{mg}$ Teva; 24.0\%; $P=0.1334)$.

\section{Adherence Effects}

Adherence rates for all DMTs were significantly higher for PSP participants $(92.9 \%$; + $31.1 \mathrm{pp}$; $n=13) \quad$ compared with non-participants (61.8\%; $n=105 ; P=0.0197$ ) (Fig. 1a). For selfinjectable DMTs, adherence rates were higher $(+19.0 \mathrm{pp})$ for PSP participants $(92.3 \% ; n=12)$ versus non-participants (73.3\%; $n=77)$ $(P=0.1339)$ (Fig. 1b); adherence effects for oral DMTs were not analyzed because of low PSP participation $(n=1)$. PSP participation was reported for six individual DMTs; adherence rates for five DMTs were higher (range: +13.5 to $+46.9 \mathrm{pp}$ ) for participants versus non-participants; for one it was similar. For DMTs with the highest reported PSP participation, 
Table 3 Patient characteristics

\begin{tabular}{|c|c|c|c|c|}
\hline \multirow[t]{2}{*}{ Patient characteristics } & \multicolumn{3}{|l|}{ PSP participation } & \multirow[t]{2}{*}{ Total } \\
\hline & PSP participants & Non-participants & $P$ value ${ }^{a}$ & \\
\hline Age(years), mean; (SD) & $42.9(7.9)$ & $44.7(10.8)$ & 0.53 & $44.6(10.6)$ \\
\hline Female/male (\%) & $71.4 / 28.6$ & $73.5 / 26.5$ & 0.86 & $73.4 / 26.6$ \\
\hline Duration current DMT (years), mean; (min-max) & $5.3(0.1-17.3)$ & $4.7(0.1-22.2)$ & 0.86 & 4.8 \\
\hline Total duration DMT (years), mean; (min-max) & $7.0(0.1-17.3)$ & $7.2(0.2-22.2)$ & 0.77 & 7.2 \\
\hline DMT, $n$ (\% PSP vs. no PSP) & $14(7.6)$ & $170(92.4)$ & & 184 \\
\hline Self-injectable DMT & $13(11.0)$ & $105(89.0)$ & & 118 \\
\hline Glatiramer acetate sc $20 \mathrm{mg}$ Teva & $1(7.7)$ & $12(92.3)$ & & 13 \\
\hline Glatiramer acetate sc $40 \mathrm{mg}$ Teva & $6(24.0)$ & $19(76.0)$ & & 25 \\
\hline Interferon beta-1a im & 0 & $16(100.0)$ & & 16 \\
\hline Peg- Interferon beta-1a sc & $1(10.0)$ & $9(90.0)$ & & 10 \\
\hline Interferon beta-1a sc $22 / 44 \mu \mathrm{g}$ & $1(4.8)$ & $20(95.2)$ & & 21 \\
\hline Interferon beta- $1 \mathrm{~b}$ sc Bayer & $4(13.3)$ & $26(86.7)$ & & 30 \\
\hline Interferon beta- $1 \mathrm{~b}$ sc Novartis & 0 & $3(100.0)$ & & 3 \\
\hline Oral DMT & $1(1.5)$ & $65(98.5)$ & & 66 \\
\hline Dimethyl fumarate & 0 & $33(100.0)$ & & 33 \\
\hline Teriflunomide & $1(3.0)$ & $32(97.0)$ & & 33 \\
\hline
\end{tabular}

$S D$ standard deviation, sc subcutaneous, im intramuscular

a $P$ values calculated using chi-square test for categorical data and $t$-test or Mann-Whitney $U$ test for continuous data

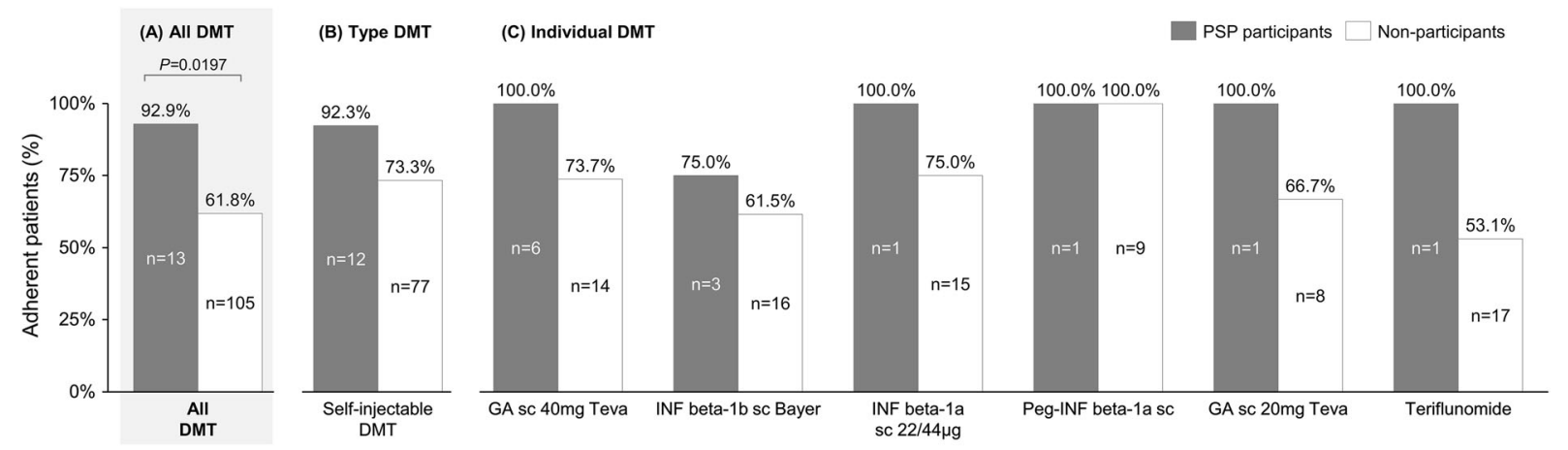

Fig. 1 Adherence rates for PSP participants vs. non-participants. $S c$ subcutaneous. $P$ values calculated using chi-square test for categorical data

adherence effects were $+26.3 \mathrm{pp}$ (GA $40 \mathrm{mg}$ Teva; $P=0.1601$ ) and +13.5 pp (INF beta- $1 \mathrm{~b} \mathrm{sc}$ Bayer; $P=0.6387$ ) (Fig. $1, C$ ). Adherence rates for DMTs with no reported PSP participation were $87.5 \%(n=14)$ for INF beta-1a im, $33.3 \%$ $(n=1)$ for INF beta-1b sc Novartis and $33.3 \%$ 
( $n=11)$ for dimethyl fumarate (data not shown). Adherence rates for non-participants were significantly higher with self-injectable DMTs $(73.3 \% ; n=77)$ compared with oral DMTs $(43.1 \% ; n=28 ; P<0.0001)$.

\section{PSP Participants' Use and Beliefs}

Of the 14 PSP participants, 11 (78.6\%) started using the PSP with current DMT initiation and 2 (14.3\%) during a period of $0.7-2.0$ years following initiation; for 1 participant (7.1\%) no information was available. Two participants (14.3\%) cited a rather frequent PSP use of one or more times weekly, 11 (78.6\%) a rather irregular, less than weekly use; for one participant (7.1\%) no information was available. The most common service type used by participants was phone services $(85.7 \% ; n=12)$. Nurse services $(42.9 \% ; n=6)$, online resources $(42.9 \% ; n=6)$ and mobile offerings $(7.1 \% ; n=1)$ were cited less often (data not shown).

Ten participants $(71.4 \%)$ considered the PSP to have a positive effect on their DMT adherence; three (21.4\%) were undecided, and no participant considered no such effect; for 1 participant $(7.1 \%)$ no information was available. Twelve participants $(85.7 \%)$ reported satisfaction with PSP services; one (7.1\%) was undecided, and no participant reported having

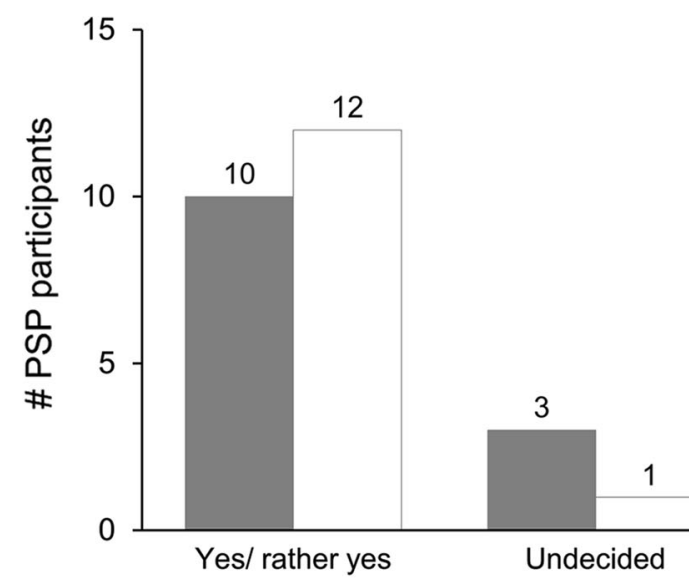

Fig. 2 PSP participant beliefs about adherence effects,

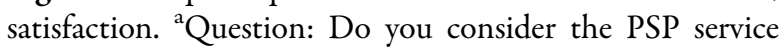
offerings of the DMT manufacturer to have a positive no satisfaction; for one participant $(7.1 \%)$ no information was available (Fig. 2).

\section{DISCUSSION}

The objective of this study was to evaluate whether PSPs have a positive impact on adherence to DMTs in mild-to-moderate RRMS across different DMTs and independent of the treatment duration on DMT. Therefore, we decided to include patients treated with a DMT supported for first-line treatment in mild-to-moderate RRMS in Germany to study a rather homogeneous patient population and spectrum of DMTs and applied a cross-sectional setup. Therefore, we chose a sensitive adherence measure and patient-reported outcomes on adherence, as assessed using DMT adherence questionnaires, as a valid and reliable measurement of real-world treatment behaviors; questionnaire return was high with $>80 \%$ consistently. By surveying PSP participation at the last visit, we consider we gained an unbiased, relevant view to evaluate adherence for PSP participants versus non-participants. Our study did not evaluate PSP impact on clinical outcomes; a positive correlation with adherence is assumed [10-12].

PSP participants showed significantly higher adherence (93\%) than non-participants (62\%); most PSP participants (71\%) also stated a belief

PSP positive adherence effect ${ }^{\mathrm{a}}$ PSP satisfaction ${ }^{b}$ 
in such an effect and mostly (86\%) satisfaction with PSP offerings. PSP participation (8\%; up to $24 \%$ for individual DMTs) and patient awareness $(22 \%)$ were surprisingly low; participation was significantly lower than data reported in earlier studies [26]. The positive adherence impact of PSPs was shown for patients with longer time on DMT treatment (mean duration: 7 years) and potentially a change of DMT. These results show that physicians should make PSP participation an integral part of the physicianpatient dialogue and actively advise patients with MS to participate in PSP, also because physicians can support patient enrollment; participation was higher in studies where physicians actively offered PSP participation [26].

Adherence rates for PSP non-participants were significantly higher with self-injectable DMTs (73\%) than with oral DMTs (43\%); results for self-injectable DMTs were consistent with those from earlier studies using similar adherence measures [14]. This shows that a more pronounced real-world adherence challenge exists with oral DMTs compared with self-injectable DMTs with longer treatment duration; earlier studies showed rather comparable adherence levels for the initial phase after DMT initiation [16]. This result is unexpected as an oral formulation is easier to administer compared with a self-injectable formulation. Furthermore, PSP participants with self-injectables DMTs reported higher adherence versus non-participants $(92 \%$; $19 \mathrm{pp})$, and PSP participation for oral DMTs was low $(<2 \%)$. This suggests that patients with self-injectable DMTs and PSP participation in the real-world setting realize higher adherence outcomes than patients with oral DMTs and, assuming a positive correlation with adherence [10-12], are more likely to achieve the desired clinical outcomes. Physicians together with their patients should consider this when deciding about MS treatment strategies.

The lower than expected PSP participation $(8 \% ; n=14)$ limited the significance of results and may introduce a bias. Furthermore, the study was not designed to evaluate PSP's impact on individual DMTs. We surveyed the use of PSP service types but did not aim at analyzing adherence effects by service type. Focused studies that analyze or compare individual DMTs may be useful to evaluate adherence effects or quality for individual PSPs. Also, this study evaluated patient-reported adherence based on pre-defined, retrospective documentation periods of 14 days at each visit, with a rather sensitive adherence measure and for DMTs with different dosing regimens, from twice daily to once every 2 weeks. We consider the 14-day period as adequate for patients to reasonably remember their dosing behavior as well as to support the sensitivity of the adherence measure across DMTs. We consider the sensitivity of the adherence measure (not missing a single dose, 100\%) as adequate for our study interest; a lower cutoff level of $80 \%$ or a different adherence measure, e.g., percent of single doses taken, may show different absolute levels of adherence but we would expect rather comparable effects for PSP participants versus non-participants. Our model cannot fully disperse differences between DMT dosing regimens; however, these exist for PSP participants and non-participants.

\section{CONCLUSIONS}

We consider this study to have shown that PSPs have a positive impact on adherence to DMTs in MS, independent of the treatment duration on DMT. The majority of patients participating in a PSP believe in this positive effect and are satisfied with PSP offerings. PSP participation and patient awareness were low, and real-world adherence levels were found to be higher with self-injectable DMTs than with oral DMTs. In summary, physicians should actively advise patients with MS to participate in PSPs and, together with their patients, consider achievable real-world adherence under different DMTs when deciding about MS treatment strategies.

\section{ACKNOWLEDGEMENTS}

Funding. This study was investigator-initiated and conducted by Charité 
Universitätsmedizin Berlin, Department of Neurology with Experimental Neurology. Funding support including the journal's Rapid Service Fee was received in the form of a grant from TEVA GmbH, Germany.

Authorship. All named authors meet the International Committee of Medical Journal Editors (ICMJE) criteria for authorship for this article, take responsibility for the integrity of the work as a whole, and have given their approval for this version to be published.

Medical Writing, Editorial and other Assistance. The authors thank the participants of the study and the participating MS centers in Berlin and Brandenburg for their pro-bono contributions with patient information and documentation: Juergen Faiss, Asklepios Hospital Teupitz; Judith Haas, Juliane Klehmet, Berlin Jewish Hospital; Judith Bellmann-Strobl, Charité Universitätsmedizin Campus Berlin-Buch; Karl Baum, Jan Doerr, Oberhavel Hospital Hennigsdorf; Klaus Tiel-Wilck, Berlin Specialist Center for Neurology (NFZB); Dorothea Becker, Steglitz Center for Neurology and Psychiatry; Said Masri, Tempelhofer Hafen Center for Neurology (NITHB). Study operations, database management and biometrics were supported by Mediveritas GmbH, Germany.

Disclosures. Lutz Harms received honoraria from Biogen, Merck-Serono, Roche, Genzyme, Bayer and Alexion for speaking, compensation as an advisory board member from Novartis, Biogen, Genzyme, Alexion, Roche and TEVA, and travel support from Bayer, Celgene and Novartis. Florian Lenz provided compensated consulting services to TEVA, outside the course of this study.

Compliance with Ethics Guidelines. The study was conducted in accordance with the Helsinki Declaration and ethics committee approvals were obtained before study initiation from Charité Universitätsmedizin Berlin (EA4/ 036/16) and the State Chamber of Medicine Brandenburg (AS60(a)/2016). Written informed consent was obtained from all individual participants included in the study.
Data Availability. The datasets generated and/or analyzed during the current study are available from the corresponding author on reasonable request and in accordance with applicable guidelines by Charité Universitätsmedizin Berlin, Germany.

Open Access. This article is licensed under a Creative Commons Attribution-NonCommercial 4.0 International License, which permits any non-commercial use, sharing, adaptation, distribution and reproduction in any medium or format, as long as you give appropriate credit to the original author(s) and the source, provide a link to the Creative Commons licence, and indicate if changes were made. The images or other third party material in this article are included in the article's Creative Commons licence, unless indicated otherwise in a credit line to the material. If material is not included in the article's Creative Commons licence and your intended use is not permitted by statutory regulation or exceeds the permitted use, you will need to obtain permission directly from the copyright holder. To view a copy of this licence, visit http://creativecommons.org/licenses/by$\mathrm{nc} / 4.0 /$.

\section{REFERENCES}

1. Noseworthy JH, Lucchinetti C, Rodriguez M, Rodriguez M, Weinshenker BG. Multiple sclerosis. N Engl J Med. 2000;343:938-52.

2. Confavreux C, Vukusic S. Natural history of multiple sclerosis: a unifying concept. Brain. 2006;129: 606-16.

3. Wallin MT, Culpepper WJ, Nichols E, et al. Global, regional, and national burden of multiple sclerosis 1990-2016: a systematic analysis for the Global Burden of Disease Study 2016. Lance Neurol. 2019;18:269-85.

4. Deutsche Gesellschaft für Neurologie. S2e Leitlinie: Diagnose und Therapie der Multiplen Sklerose [S2e guideline: diagnosis and therapy of multiple sclerosis]. https://www.dgn.org/leitlinien/2333-11-312012-diagnose-und-therapie-der-multiplensklerose. Accessed 05 Apr 2019. 
5. Holstiege J, Steffen A, Goffrier B, Bätzing J. Epidemiologie der MS. Eine populationsbasierte deutschlandweite Studie [Epidemiology of MS. A population-based study troughout Germany]. Zentralinstitut für die Kassenärztliche Versorgung in Deutschland, Versorgungsatlas-Bericht Nr. 17/09. Berlin, 2017. doi: 10.20364/VA-17.09.

6. Montalban X, Gold R, Thompson AJ, et al. ECTRIMS/EAN Guideline on the pharmacological treatment of people with multiple sclerosis. Mult Scler J. 2018;24:96-120.

7. European Medicines Agency. https://www.ema. europa.eu/en/medicines/field_ema_web_ categories\%253Aname_field/Human/ema_group_ types/ema_medicine/field_ema_med_status/ authorised-36/search_api_aggregation_ema_ therapeutic_area_name/Multiple\%20Sclerosis. Accessed 13 Mar 2019.

8. European Medicines Agency. https://www.ema. europa.eu/en/documents/psusa/glatiramer-listnationally-authorised-medicinal-products-psusa/ 00001529/201711_en.pdf. Accessed 13 Mar 2019.

9. Ghezzi A. European and American guidelines for multiple sclerosis treatment. Neurol Ther. 2018;7: 189-94.

10. Tan H, Cai Q, Agarwal S, Stephenson JJ, Kamat S. Impact of adherence to disease-modifying therapies on clinical and economic outcomes among patients with multiple sclerosis. Adv Ther. 2011;28:51-61.

11. Cohen BA, Coyle PK, Leist T, Oleen-Burkey MA, Schwartz M, Zwibel H. Therapy optimization in multiple sclerosis: a cohort study of therapy adherence and risk of relapse. Mult Scler Relat Disord. $2015 ; 4: 75-82$.

12. Burks J, Marshall TS, Ye X. Adherence to diseasemodifying therapies and its impact on relapse, health resource utilization, and costs among patients with multiple sclerosis. Clinicoecon Outcomes Res. 2017;9:251-60.

13. Treadaway K, Cutter G, Salter A, et al. Factors that influence adherence with disease-modifying therapy in MS. J Neurol. 2009;256:568-76.

14. Devonshire V, Lapierre Y, Macdonell R, et al. The Global Adherence Project (GAP): a multicenter observational study on adherence to disease-modifying therapies in patients with relapsing-remitting multiple sclerosis. Eur J Neurol. 2011;18:69-77.

15. Menzin J, Caon C, Nichols C, White LA, Friedman M, Pill MW. Narrative review of the literature on adherence to disease-modifying therapies among patients with multiple sclerosis. J Manag Care Pharm. 2013;19(1 Suppl A):S24-S40.
16. Munsell M, Frean M, Menzin J, Phillips AL. An evaluation of adherence in patients with multiple sclerosis newly initiating treatment with a self-injectable or an oral disease-modifying drug. Patient Prefer Adherence. 2017;11:55-62.

17. Johnson KM, Zhou H, Lin F, Ko JJ, Herrera V. Realworld adherence and persistence to oral diseasemodifying therapies in multiple sclerosis patients over 1 year. J Manag Care Spec Pharm. 2017;23: 844-52.

18. Yoon EL, Cheong WL. Adherence to oral diseasemodifying therapy in multiple sclerosis patients: a systematic review. Mult Scler Relat Disord. 2019;28: 104-8.

19. Bayer, BETAPLUS Programm. https://www.msgateway.de/patienten/betaplus. Accessed 30 Jun 2019.

20. Biogen, MS Service Programm. https://www.ms-life. de/ms-service/. Accessed 30 Jun 2019.

21. MerckSerono, ADVEVA Programm: https://www. leben-mit-ms.de/service. Accessed 30 Jun 2019.

22. Mylan, MeinService Programm, https://www.meinms-service.de/de-de/patienten. Accessed 30 Jun 2019.

23. Novartis, MSUNDICH Programm. https://www. msundich.de/fuer-patienten/service/uebersicht/. Accessed 30 Jun 2019.

24. Sanofi-Genzyme, MS-Begleiter Programm. https:// ms-begleiter.de/Patient/Login\#. Accessed 30 Jun 2019.

25. Teva, Aktiv-mit-MS Programm. https://www.aktivmit-ms.de/aktiv-mit-ms-programm/. Accessed 30 Jun 2019.

26. Katsarava Z, Ehlken B, Limmroth V, et al. Adherence and cost in multiple sclerosis patients treated with IM IFN beta-1a: impact of the CARE patient management program. BMC Neurol. 2015;15:170.

27. Jones JL, Scheidt DJ, Kaushal RS, Carroll CA. Assessing the role of patient support services on adherence rates in patients using glatiramer acetate for relapsing-remitting multiple sclerosis. J Med Econ. 2013;16:213-20.

28. Roche J, McCarry Y, Mellors K. Enhanced patient support services improve patient persistence with multiple sclerosis treatment. Patient Prefer Adherence. 2014;8:805-11.

29. Monterroso J, Curlis J, Gribben L. THUR 180 Patient support program for RRMS patients treated with DMF. J Neurol Neurosurg Psychiatry. 2018;89:A24. 
30. Kohlmann T, Wang C, Lipinski J, et al. The impact of a patient support program for multiple sclerosis on patient satisfaction and subjective health status. J Neurosci Nurs. 2013;45:E3-14.
31. Freidel M, Ortler S, Fuchs A, Seibert S, Schuh K. Acceptance of the extracare program by beta interferon-treated patients with multiple sclerosis: results of the explore study. J Neurosci Nurs. 2015;47:E31-39. 